\title{
The association between fluid intake, water balance and body composition
}

\author{
Ana Laja-García, María de Lourdes Samaniego-Vaesken, Carmen Moráis-Moreno, \\ Teresa Partearroyo and Gregorio Varela-Moreiras \\ Departamento de Ciencias Farmacéuticas y de la Salud, Facultad de Farmacia, Universidad San Pablo-CEU, CEU \\ Universities, Madrid, Spain
}

\begin{abstract}
Introduction: The increasing prevalence of overweight and obesity has developed into an epidemic public health problem worldwide. In this regard, in the last years several investigations have suggested that water intake and water balance could have important implications for both weight management and body composition. The aim of this study was to analyse the association between fluid intake, water balance and body composition in a sample of healthy young adults from Spain.
\end{abstract}

Material and methods: A total of 358 healthy subjects (121 males; 237 females) aged 18-39 years participated in the current study. The validated questionnaire entitled "The hydration status questionnaire" was used to assess fluid intake, elimination, and water balance. Anthropometric measurements (height, weight and waist circumference) were performed according to the recommendations of the International Standards for Anthropometric Assessment (ISAK). The estimates of total body water (TBW), fat mass (FM) and fat free mass (FFM) were acquired by bioelectrical bioimpedance analysis. Physical activity was estimated through the Short form of the International Physical Activity Questionnaire (IPAQ-SF). Differences in anthropometric and body composition variables were assessed through the ANOVA test and considered significant at $\mathrm{p}<0.05$.

Results: Fluid intake was correlated with body water content in females $(r=0.180, p=0.006)$ and males $(r=0.266$, $p=0.003)$. An inverse association between water consumption per weight $(\mathrm{ml} / \mathrm{kg})$ with body weight (females $(\mathrm{f}): \mathrm{r}=-0.318, \mathrm{p}=0.000 ; \mathrm{males}(\mathrm{m})$ : $r=-0.220, p=0.015)$, body fat mass ( $\mathrm{f}: \mathrm{r}=-0.320, \mathrm{p}=0.000 ; \mathrm{m}: \mathrm{r}=-0.200, \mathrm{p}=0.028)$, and waist circumference $(\mathrm{f}: \mathrm{r}=-0.237, \mathrm{p}=$ $0.000 ; \mathrm{m}: \mathrm{r}=-0.215, \mathrm{p}=0.018$ ) was found. Finally, significant differences in body water content in females according to water balance were observed $(\mathrm{p}=0.04)$.

Discussion: Higher fluid intake seems to be related with a better body composition, therefore the improvement of water intake and water balance could be useful in weight management and in the prevention of overweight and obesity in healthy young adults.

\section{Conflict of Interest}

The authors declare no conflict of interest 